\title{
Cochlear implantation in far-advanced otosclerosis: hearing results and complications
}

\author{
Impianto cocleare nell'otosclerosi in fase avanzata: risultati uditivi e complicanze
}

\author{
A. RIBADEAU DUMAS ${ }^{1}$, A.T. SCHWALJE², V. FRANCO-VIDAL ${ }^{1}$, J.P. BÉBÉAR ${ }^{1}$, V. DARROUZET¹, \\ D. BONNARD 1 \\ ${ }^{1}$ Department of Otorhinolaryngology and Skull Base Surgery, Pellegrin University Hospital F-33000, University \\ of Bordeaux, France; ${ }^{2}$ Department of Otolaryngology, Head and Neck Surgery, University of lowa Hospitals and \\ Clinics, lowa City, USA
}

\section{SUMMARY}

Severe forms of otosclerosis known as far-advanced otosclerosis (FAO) can lead to severe to profound sensorineural hearing loss and can justify cochlear implantation. Because of the pathophysiology of otosclerosis, patients implanted for FAO may experience an increased rate of complications, such as facial nerve stimulation or electrode dislocation, and may have poorer hearing outcomes than expected. This retrospective study aimed to compare cochlear implantation hearing outcomes, surgical difficulties and complications in FAO patients versus non-FAO patients. Moreover, we evaluated whether high resolution computed tomography (CT scan) findings were predictive of perioperative problems, complications and hearing outcomes. FAO patients were diagnosed based on medical history, examination and CT scan. Thirty-five ears from FAO patients were compared to 38 control ears. Audiometric results were assessed at least 12 months after implantation by pure tone average, speech reception threshold, monosyllabic and disyllabic word recognition score (WRS) and Central Institute for the Deaf (CID) sentences test. Complications and surgical difficulties were compiled. CT scan findings were categorised within 3 grades of otosclerotic extension. No significant difference was found between FAO and non-FAO hearing outcomes, except that monosyllabic WRS were lower for FAO patients, especially those who underwent previous stapedotomy. Facial nerve symptomatology occurred in $8.6 \%$ of FAO patients; among these, one required explantation-reimplantation surgery. $86 \%$ of FAO implanted patients had retrofenestral extension on CT. These were associated with poorer disyllabic WRS (51\% vs $68 \%$, $\mathrm{p}<0.05)$ than those with only fenestral involvement. Although not significant, high grade of severity on CT tended to be associated with surgical difficulties and complications. Cochlear implantation in FAO patients is an effective treatment technique. Though the overall complication rate is low, it tends to be higher in cases of severe extension on CT. Patient counselling should be adjusted accordingly.

KEY WORDS: Cochlear implantation • Otosclerosis • Speech perception • Computed tomography • Facial nerve injuries

\section{RIASSUNTO}

Molte forme di otosclerosi, riconosciute come far-advanced otosclerosis (FAO) presentano un'ipoacusia neurosensoriale grave o profonda, e possono giustificare un impianto cocleare. A causa della fisiopatologia stessa dell'otosclerosi, i pazienti impiantati per FAO potrebbero andare incontro più frequentemente a complicanze, come stimolazione del nervo faciale, dislocazione dell'elettrodo, e potrebbero avere dei risultati uditivi peggiori rispetto a quelli attesi. Questo studio retrospettivo si è posto l'obiettivo di confrontare i risultati uditivi dell'impianto cocleare, le difficoltà chirurgiche e le complicanze tra pazienti con FAO e pazienti senza FAO. Inoltre, abbiamo valutato se la TC ad alta risoluzione fosse predittiva di problemi perioperatori, complicanze, e risultati uditivi. Trentacinque orecchie dei pazienti con FAO sono state confrontate con 38 orecchie di controllo. I risultati audiometrici sono stati valutati almeno 12 mesi dopo l'impianto attraverso la soglia media per toni puri e la soglia di ricezione del linguaggio, il "monosyllabic and disyllabic word recognition score" (WRS) e il "Central Institute for the Deaf sentences test" (CID). Sono state annotate le complicanze e le difficoltà chirurgiche. I quadri TC sono stati classificati in tre gradi di estensione otosclerotica. Non sono state riscontrate differenze significative tra i risultati audiometrici dei pazienti con FAO e dei pazienti senza FAO, ad eccezione del WRS monosillabico, più basso nei pazienti con $F A O$, specialmente in coloro sottoposti precedentemente a stapedotomia. Segni e sintomi riferibili a danni del nervo faciale si sono verificati nell' $8,6 \%$ dei pazienti con FAO; tra questi, un solo paziente è stato sottoposto a chirurgia di espianto-reimpianto. L'86\% dei pazienti con FAO impiantati avevano un'otosclerosi retrofenestrale alle immagini TC, il che si associava ad un WRS bisillabico inferiore (51\% vs $68 \%, p<0,05)$ rispetto ai pazienti con coinvolgimento esclusivamente fenestrale. Quadri TC gravi tendevano ad associarsi a difficoltà chirurgiche e complicanze, anche se non in maniera statisticamente significativa. In conclusione l'impianto cocleare nei pazienti con FAO è un'opzione di trattamento efficace. Benché il tasso di complicanze sia basso, queste tendono ad aumentare in caso di quadri severi alla TC.

PAROLE CHIAVE: Impianto cocleare $\bullet$ Otosclerosi $\bullet$ Percezione del linguaggio $\bullet$ Tomografia computerizzata $\bullet$ Danni del nervo faciale 


\section{Introduction}

Otosclerosis is an osteodystrophy that affects the bone of the otic capsule. In a normal inner ear, this bone is supposed to be free from osteoclastic and osteoblastic phenomenon. However, otosclerosis is associated with a continuous process of osteolysis and osteogenesis leading to a peculiar histology including vascular proliferation, bone resorption and new formation of connective tissue stroma ${ }^{12}$. The mean prevalence in the Caucasian population is $1 / 3000$. According to pathophysiological research, several aetiological factors may be involved, including heredity, genetics, hormones and viral infection ${ }^{3}$.

Otosclerosis prefers the fissula ante fenestram. When it reaches the footplate, conductive hearing loss appears: at this stage of the disease, hearing aids or stapedotomy, or both, are generally indicated to improve hearing.

In about $10 \%$ of the otosclerotic population sensorineural hearing loss occurs ${ }^{45}$, concomitant with the progression of the osteodystrophy to the lateral wall of the cochlear endosteum. One hypothesis postulates that the atrophy of the stria vascularis and spiral ligament, which leads to an ionic perturbation of the endolymph, is responsible for hair cell dysfunction ${ }^{26}$.

In 1961, House and Sheehy described FAO as a clinical diagnosis of otosclerosis associated with an air-conduction threshold above $85 \mathrm{~dB}$ without a measurable bone conduction threshold ${ }^{7}$. In 2011, Merkus et al. ${ }^{8}$ added the necessity of a speech reception threshold (SRT) decrease. When sensorineural hearing loss is profound and WRS is under $50 \%$ at $60 \mathrm{~dB}$ with efficient hearing aids, the patient may meet clinical cochlear implantation criteria. Thus, at the FAO stage, management algorithms include stapedotomy in addition to efficient hearing aids, or cochlear implantation.

As shown in several studies describing hearing improvement after stapedotomy in patients with severe to profound hearing loss, stapedotomy combined with hearing aids does not lead to many complications, and is relatively low cost, efficient and effective (post-operative disyllabic WRS at $60 \mathrm{~dB}=50.6 \%$ for Kabbara et al.) ${ }^{9}$. Moreover, stapes surgery does not preclude further cochlear implantation ${ }^{4910}$.

Nevertheless, cochlear implantation is also effective in the management of severe to profound congenital or acquired hearing loss, including otosclerosis. Thanks to the standardisation of the procedure, the complication rate is low and audiometric outcomes continue to improve (disyllabic WRS at $60 \mathrm{~dB}=72.8 \%$ for Kabbara et al.) ${ }^{9}$. However, among all the various aetiologies requiring cochlear implantation, FAO suffers from a relatively high rate of complications, most commonly electrode dislocation and facial nerve stimulation. The latter may be the result of current flow from the electrode to the facial nerve because of the lower impedance of the otosclerotic bone between the facial nerve canal and the upper basal turn of the cochlea ${ }^{911}$. Thus, the management of FAO patients remains difficult, as the clinician and patient must balance audiometric outcomes, complication rates and economic issues. Most studies evaluating cochlear implantation in otosclerosis have not taken into account radiologic criteria for diagnosis of disease. Therefore, the incidence of complications for cochlear implantation in the otosclerotic population might have been overestimated or underestimated due to sampling error. Typically, only post-mortem histological findings can objectively confirm a diagnosis of otosclerosis. Consequently, during a patient's lifetime a diagnosis can be suspected when certain criteria such as radiological findings are met. As the sensitivity and specificity of high resolution CT in otosclerosis are $95 \%$ and 99\% respectively (according to Marx et al.) ${ }^{12}$, the probability of having severe otosclerosis like FAO in the presence of a normal CT scan is low. CT confirms the otosclerotic focus, and can rule out other causes of conductive or mixed hearing loss with a normal tympanic membrane: fixation of the head of the malleus to the wall of the tympanic cavity, dystrophy or blocking of the ossicular chain, or inner ear malformation. Consequently, CT is now fundamental in the initial workup of otosclerosis. In addition, MRI is often performed on implant candidates to evaluate endosteal involvement and exclude a retro-cochlear pathology.

This study aimed to evaluate cochlear implantation outcomes in FAO patients whose diagnosis was supported by CT findings, and to compare audiometric outcomes, complication rates and peri-operative problems with a non-FAO control group. In addition, we analysed whether preoperative radiological findings were predictive of adverse effects and hearing outcomes.

\section{Materials and methods}

This is a retrospective study including adult implanted patients from our centre operated on from 1997 to 2015.

\section{Patient selection}

A diagnosis of FAO was made using typical clinical history of progressive hearing loss, normal otoscopic examination, audiometry showing a severe to profound hearing loss without acoustic reflex and typical CT findings. Patients with normal or absent radiologic data were excluded. Patients who previously underwent stapes surgery were included. 
26 FAO patients were compared to a non-FAO control group of 30 post-lingually deafened patients selected from the same cochlear implant database. The two groups were comparable for sex, age at implantation, period of implantation and time of hearing deprivation, and the control group was implanted for other aetiologies than otosclerosis (e.g., progressive idiopathic, progressive familial, traumatic, or Menière's disease). They all had undergone standard evaluation before cochlear implantation and met criteria for implantation: a severe to profound sensorineural hearing loss associated with a speech discrimination threshold under $50 \%$ for words at $60 \mathrm{~dB}$ with efficient hearing aids.

\section{Surgical technique}

Two experienced members of our surgical team performed the surgery under general anaesthesia. Facial nerve monitoring was used in all cases. In most cases, a facial recess approach was performed in order to access the round window. When a bony wall made the access to the round window membrane difficult, it was carefully drilled out; if ossification of the basal turn was encountered, a drill-out was performed until luminal permeability was found. After local steroid injection, the electrode array was inserted into the scala tympani using minimally traumatic techniques. Finally, the internal receiver/stimulator was fixed in a subperiosteal temporal pocket and the ground electrode, if present, was placed underneath the temporalis muscle. The position of the electrode array was confirmed by skull radiography immediately after the procedure. Surgical findings such as round window ossification, incomplete insertion, or misplacement of the electrode array were recorded. Devices from four manufacturers were implanted. Only straight electrode arrays were used.

\section{Outcome assessment}

Demographic and clinical data such as sex, deafness aetiology, age of implantation, time of hearing deprivation and previous stapes surgery were recorded. The following audiometric data were collected in our department at least 12 months after implantation: post-operative pure tone average (mean PTA, calculated by averaging the airconduction thresholds at 500, 1000 and $2000 \mathrm{~Hz}$ ), speech reception threshold (SRT) as the decibel level at which $50 \%$ of words could be repeated by the subject, monosyllabic and disyllabic WRS and a French translated version of the CID sentences test. Words and sentences were presented at $60 \mathrm{~dB}$.

Adverse effects such as facial palsy or stimulation (even if temporary), vertigo, tinnitus, dysgeusia, or infections, as reported in the medical record during follow-up clinical appointments, were compiled. For bilaterally implanted patients, surgeries had been performed sequentially, and each ear was considered independently.

\section{Imaging data}

High resolution CT scans of temporal bones were analysed by three experienced neuroradiologists. FAO patients were classified in three grades as follows: grade 1, otosclerotic focus anterior to the oval window or thickened footplate; grade 2, patchy retrofenestral involvement of the disease to the cochlea or around the cochlear otic capsule; grade 3, diffuse involvement to the otic capsule. These grades correspond to the main categories of Rotteveel's ${ }^{13} 14$ radiographic classification.

\section{Data analysis}

As demographic and audiometric data of both groups did not follow a normal distribution, we used non-parametric tests such as the Mann-Whitney U-test, Wilcoxon signedrank test and Fisher's exact test to compare them. In order to evaluate the correlation between CT scan grade and hearing performance, we used the non-parametric Kruskal-Wallis test. Age, time of hearing deprivation and hearing outcomes are expressed as means \pm SD. The level of statistical significance was $\mathrm{p}<0.05$.

\section{Results}

\section{Demographic data}

26 patients with 35 implanted ears ( 9 bilaterally implanted) were included in the FAO group. Among these, 8 had previous stapedotomy. Thirty non-otosclerotic patients with 38 implanted ears ( 8 bilaterally implanted) were selected as controls.

Considering each ear independently, the two groups did not differ for age at implantation (59 years \pm 8 in the FAO group, 55 years \pm 9 in the non-FAO group, Wilcoxon test $\mathrm{p}=0.10)$, sex ratio $(\mathrm{FAO} \mathrm{SR}=1.18$, non-FAO SR $=0.9$, Fisher's exact test $\mathrm{p}=0.55$ ), or time of hearing deprivation (3.5 years \pm 7.8 in the FAO group, 1.5 years \pm 3.6 in the non-FAO group, Wilcoxon test $\mathrm{p}=0.08$ ). Detailed demographic data are presented in Table I.

\section{Peri- and post-operative clinical data}

Surgical difficulties were encountered in 18 of the $73 \mathrm{im}$ planted ears (24.6\%): 3 FAO patients (2 CT scan grade 2, 1 grade 3 ) necessitate round window or basal turn extra drilling until the scala tympani was properly identified, 1 FAO patient (grade 2) with electrode misplacement and 8 incomplete electrode insertions in the FAO group (1 grade 1, 2 grade 2, 5 grade 3). In addition, there were 6 incom- 
plete electrode insertions in the non-FAO group. Detailed data for the FAO group are presented in Table I.

The difference in incidence of surgical difficulty between both groups was not significant (Fisher's exact test $\mathrm{p}=0.10$ ). In addition, no significant correlation was found between the severity of the CT scan and incidence of surgical complications (Kruskal-Wallis test $\mathrm{p}>0.05$ ).
Facial symptomatology occurred in both groups: temporary facial palsy occurred in 2 FAO patients, classified grade 2 and 3 on CT scan, and in one non-FAO patient. One FAO patient had persistent facial nerve stimulation even after deactivation of several electrodes; this patient required a revision surgery. He was classified grade 3 on CT scan.

Table I. Demographic, radiographic and surgical data for the FAO group.

\begin{tabular}{|c|c|c|c|c|c|c|c|c|c|c|}
\hline$N$ & Bilateral & Gender & $\begin{array}{c}\text { Age at } \\
\text { implantation } \\
\text { (year) }\end{array}$ & $\begin{array}{l}\text { Hearing } \\
\text { deprivation } \\
\text { (year) }\end{array}$ & CT grade & $\begin{array}{l}\text { Incomplete } \\
\text { insertion }\end{array}$ & Stapedotomy & $\begin{array}{c}\text { Facial } \\
\text { symptomatology }\end{array}$ & $\begin{array}{l}\text { Electrode } \\
\text { dislocation }\end{array}$ & $\begin{array}{l}\text { Cochlear } \\
\text { ossification }\end{array}$ \\
\hline 1 & Y & M & 60 & 20 & 3 & N & N & N & N & $\mathrm{N}$ \\
\hline 2 & Y & M & 62 & 0 & 1 & $\mathrm{~N}$ & Y & N & $\mathrm{N}$ & $\mathrm{N}$ \\
\hline 3 & $\mathrm{~N}$ & $\mathrm{~F}$ & 62 & 0 & 2 & $\mathrm{~N}$ & $\mathrm{~N}$ & Y & $\mathrm{N}$ & $\mathrm{N}$ \\
\hline 4 & Y & M & 53 & 3 & 2 & Y & N & N & N & Y \\
\hline 5 & Y & M & 53 & 3 & 2 & N & $\mathrm{N}$ & N & $\mathrm{N}$ & Y \\
\hline 6 & $\mathrm{~N}$ & $\mathrm{~F}$ & 56 & 1 & 2 & $\mathrm{~N}$ & $\mathrm{~N}$ & $\mathrm{~N}$ & $\mathrm{~N}$ & $\mathrm{~N}$ \\
\hline 7 & $\mathrm{~N}$ & M & 51 & 1 & 1 & $\mathrm{~N}$ & $\mathrm{~N}$ & N & $\mathrm{N}$ & $\mathrm{N}$ \\
\hline 8 & $\mathrm{~N}$ & M & 66 & 0 & 3 & $\mathrm{~N}$ & $\mathrm{~N}$ & N & $\mathrm{N}$ & Y \\
\hline 9 & $\mathrm{~N}$ & $\mathrm{~F}$ & 70 & 0 & 3 & $Y$ & Y & N & $\mathrm{N}$ & $\mathrm{N}$ \\
\hline 10 & Y & M & 49 & 10 & 3 & $\mathrm{~N}$ & $\mathrm{~N}$ & $\mathrm{~N}$ & $\mathrm{~N}$ & $\mathrm{~N}$ \\
\hline 11 & Y & M & 53 & 0,5 & 3 & $\mathrm{~N}$ & $\mathrm{~N}$ & $\mathrm{~N}$ & $\mathrm{~N}$ & $\mathrm{~N}$ \\
\hline 12 & $Y$ & $M$ & 72 & 0 & 3 & $N$ & $\mathrm{~N}$ & $N$ & $\mathrm{~N}$ & $\mathrm{~N}$ \\
\hline 13 & Y & $M$ & 75 & 0 & 3 & $Y$ & $Y$ & $N$ & $\mathrm{~N}$ & $\mathrm{~N}$ \\
\hline 14 & $\mathrm{~N}$ & $F$ & 69 & 0 & 3 & $Y$ & $\mathrm{~N}$ & $N$ & $\mathrm{~N}$ & $\mathrm{~N}$ \\
\hline 15 & $\mathrm{~N}$ & $\mathrm{~F}$ & 53 & 0 & 3 & $\mathrm{~N}$ & $\mathrm{~N}$ & $\mathrm{~N}$ & $\mathrm{~N}$ & $\mathrm{~N}$ \\
\hline 16 & $\mathrm{~N}$ & $\mathrm{~F}$ & 52 & 0 & 2 & $Y$ & $\mathrm{~N}$ & $N$ & $\mathrm{~N}$ & $\mathrm{~N}$ \\
\hline 17 & $\mathrm{~N}$ & $\mathrm{~F}$ & 49 & 1 & 1 & $N$ & $\mathrm{~N}$ & $N$ & $\mathrm{~N}$ & $\mathrm{~N}$ \\
\hline 18 & $\mathrm{~N}$ & $\mathrm{~F}$ & 58 & 0 & 3 & $\mathrm{~N}$ & $\mathrm{~N}$ & $\mathrm{~N}$ & $\mathrm{~N}$ & $\mathrm{~N}$ \\
\hline 19 & $\mathrm{~N}$ & $\mathrm{~F}$ & 71 & 0 & 3 & $\mathrm{~N}$ & Y & $\mathrm{N}$ & $\mathrm{N}$ & $\mathrm{N}$ \\
\hline 20 & $Y$ & $\mathrm{~F}$ & 47 & 0 & 3 & $\mathrm{~N}$ & $\mathrm{~N}$ & $\mathrm{~N}$ & $\mathrm{~N}$ & $\mathrm{~N}$ \\
\hline 21 & $Y$ & $\mathrm{~F}$ & 58 & 10 & 3 & $\mathrm{~N}$ & $\mathrm{~N}$ & $\mathrm{~N}$ & $\mathrm{~N}$ & $\mathrm{~N}$ \\
\hline 22 & $Y$ & $F$ & 66 & 0 & 1 & $Y$ & $\mathrm{~N}$ & $\mathrm{~N}$ & $\mathrm{~N}$ & $\mathrm{~N}$ \\
\hline 23 & $Y$ & $\mathrm{~F}$ & 62 & 10 & 1 & $\mathrm{~N}$ & $Y$ & $\mathrm{~N}$ & $\mathrm{~N}$ & $\mathrm{~N}$ \\
\hline 24 & $Y$ & $M$ & 66 & 2 & 3 & $\mathrm{~N}$ & $\mathrm{~N}$ & $\mathrm{~N}$ & $\mathrm{~N}$ & $\mathrm{~N}$ \\
\hline 25 & Y & $M$ & 67 & 0 & 2 & $\mathrm{~N}$ & $\mathrm{~N}$ & $\mathrm{~N}$ & $\mathrm{~N}$ & $\mathrm{~N}$ \\
\hline 26 & $Y$ & $M$ & 54 & 0 & 2 & $\mathrm{~N}$ & $N$ & $N$ & $Y$ & $\mathrm{~N}$ \\
\hline 27 & Y & $M$ & 54 & 0 & 2 & $\mathrm{~N}$ & $\mathrm{~N}$ & $\mathrm{~N}$ & $\mathrm{~N}$ & $\mathrm{~N}$ \\
\hline 28 & $\mathrm{~N}$ & $F$ & 69 & 39 & 3 & $\mathrm{~N}$ & $\mathrm{~N}$ & $\mathrm{~N}$ & $\mathrm{~N}$ & $\mathrm{~N}$ \\
\hline 29 & $\mathrm{~N}$ & $\mathrm{M}$ & 62 & 1 & 2 & $\mathrm{~N}$ & $N$ & $\mathrm{~N}$ & $N$ & $\mathrm{~N}$ \\
\hline 30 & $\mathrm{~N}$ & $\mathrm{M}$ & 47 & 1 & 2 & $\mathrm{~N}$ & $\mathrm{~N}$ & $\mathrm{~N}$ & $\mathrm{~N}$ & $\mathrm{~N}$ \\
\hline 31 & $\mathrm{~N}$ & $F$ & 46 & 5 & 3 & $\mathrm{~N}$ & $Y$ & $N$ & $N$ & $\mathrm{~N}$ \\
\hline 32 & $Y$ & $M$ & 45 & 1 & 3 & $\mathrm{~N}$ & $\mathrm{~N}$ & $Y$ & $\mathrm{~N}$ & $\mathrm{~N}$ \\
\hline 33 & Y & $M$ & 60 & 15 & 3 & Y & $Y$ & $Y$ & $N$ & $\mathrm{~N}$ \\
\hline 34 & $\mathrm{~N}$ & $M$ & 64 & 0 & 2 & $Y$ & $N$ & $N$ & $N$ & $\mathrm{~N}$ \\
\hline 35 & $\mathrm{~N}$ & $\mathrm{~F}$ & 50 & 0 & 3 & $\mathrm{~N}$ & Y & $\mathrm{N}$ & $\mathrm{N}$ & $\mathrm{N}$ \\
\hline
\end{tabular}

Bilateral, ears from bilaterally implanted patients; $Y, Y$ Yes; $N$, No. 
Four patients required revision surgery within a year following the initial surgery. Three of these were in the FAO group: one the day after the implant surgery for electrode dislocation in the superior semi-circular canal (grade 2), one because of facial nerve stimulation (grade 3) and one for infection 6 months after surgery. One patient in the non-FAO group also required revision surgery for infection.

Patients did not complain of dysgeusia or vertigo. Sixtythree percent of implanted patients suffered from preoperative tinnitus ( 26 in the FAO group, 20 in the non-FAO group), while after surgery only $37 \%$ complained of tinnitus (14 FAO patients, 13 non-FAO patients). This improvement was significant (Mann Whitney $\mathrm{p}=0.001$ ) but there was no association between aetiology of deafness and presence of preoperative tinnitus (Fischer exact test $p>0.05$ ), hearing outcomes, or presence of post-operative tinnitus (Mann Whitney $\mathrm{p}>0.05$ for all comparisons).

\section{Hearing outcomes}

Twelve months after surgery the mean PTA was $28 \mathrm{~dB} \pm 8$ in the FAO group and $26 \mathrm{~dB} \pm 8$ in the non-FAO group. The mean SRT was $33 \mathrm{~dB} \pm 10$ and $32 \mathrm{~dB} \pm 14$ in the FAO and non-FAO group, respectively (Fig. 1). In the FAO group the mean monosyllabic, disyllabic and CID sentences recognition scores were $53 \% \pm 30,68 \% \pm 28$, and $76 \% \pm 28$, respectively. In the non-FAO group, they were $67 \% \pm 25,67 \% \pm 29$, and $85 \% \pm 20$, respectively (Fig. 2). There was no statistical difference between both groups for hearing outcomes (Mann-Whitney $\mathrm{p}>0.05$ for each comparison) except for the monosyllabic WRS which was

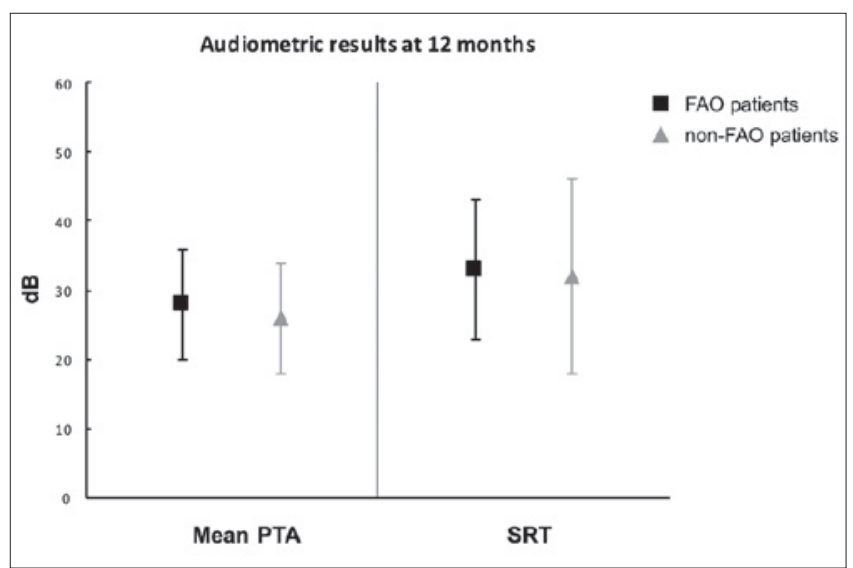

Fig. 1. Audiometric results at 12 months for far-advanced otosclerosis (FAO, black squares) and non-FAO (grey triangles) patients. Mean PTA: averaged pure tone audiometric thresholds at 500, 1000 and $2000 \mathrm{~Hz}$ (in dB); SRT: speech reception threshold.

Comparative analysis was performed and found no significant difference between groups (Mann-Whitney, $p>0.05$ ).

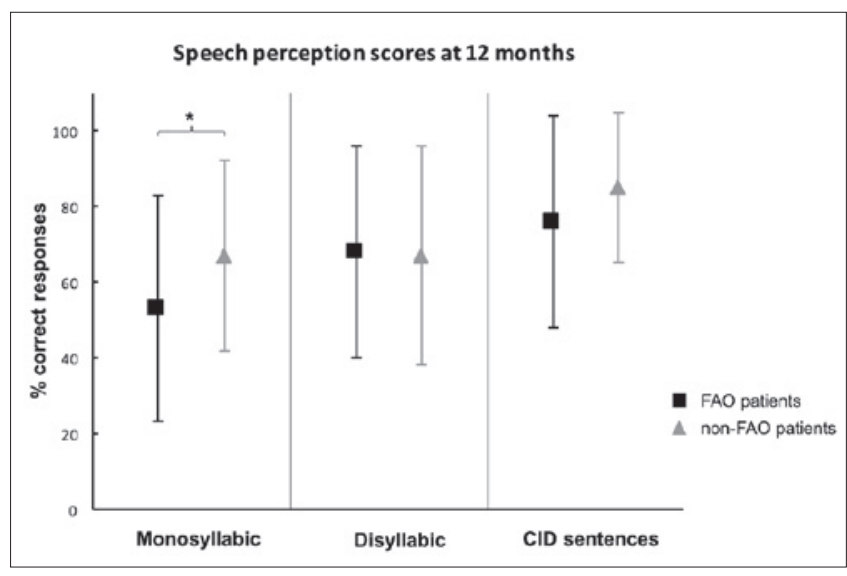

Fig. 2. Mean speech perception scores at 12 months for far-advanced otosclerosis (FA0, black squares) and non-FA0 (grey triangles) patients. The percentage of correct responses is shown for monosyllabic words, disyllabic words and Central Institute for the Deaf sentences (CID); Comparative analysis on each score revealed a significant difference between FAO and non-FAO patients for monosyllabic word recognition score (Mann-Whitney, $p<0.05)$.

significantly better in the non-FAO group (Mann-Whitney $\mathrm{p}=0.042$ ).

Within the FAO group, patients who underwent previous stapedotomy had poorer audiometric outcomes than the other FAO patients, with mean PTA $30 \mathrm{~dB} \pm 4$ vs $27 \mathrm{~dB} \pm 8$, SRT $39 \mathrm{~dB} \pm 10$ vs $31 \mathrm{~dB} \pm 8$, monosyllabic WRS $30 \% \pm 26 v s 60 \% \pm 27$, disyllabic WRS $47 \% \pm 35$ vs $74 \% \pm 23$, and CID sentences score $54 \% \pm 38$ vs $82 \% \pm 21$. Only the monosyllabic WRS showed a significant difference (Mann Whitney $p=0.013$ ). This difference remained significant even when comparing FAO / previous stapedotomy to all other FAO and non-FAO patients (Mann Whitney $\mathrm{p}=0.003$ ). Demographic analysis revealed a slightly higher mean age at implantation in the group of FAO patients with stapedotomy than in the others: 62 years $v s 57$ years in FAO patients without previous stapedotomy (Mann Whitney $\mathrm{p}=0.25$ ) and 55 years in non-FAO patients $(\mathrm{p}=0.07)$. There was no statistically significant difference in radiographic $\mathrm{CT}$ grade severity between patients with or without previous stapedotomy (6 grade 3, 2 grade 1, Chi Square $\mathrm{p}=0.09$ ).

Overall, hearing outcomes were slightly better when the electrode insertion was complete than when it was partial: mean PTA $26 \mathrm{~dB} \pm 7$ vs $31 \mathrm{~dB} \pm 8$ (Mann Whitney $\mathrm{p}=0.07)$, SRT $32 \mathrm{~dB} \pm 13$ vs $34 \mathrm{~dB} \pm 7(\mathrm{p}=0.26)$, monosyllabic WRS 63\% \pm 26 vs 49\% $\pm 34(\mathrm{p}=0.13)$, disyllabic WRS $69 \% \pm 28 v s 62 \% \pm 26(\mathrm{p}=0.33)$ and CID sentences score $84 \% \pm 22$ vs $68 \% \pm 29(\mathrm{p}=0.046)$.

Considering each ear independently, ears from bilaterally implanted patients had significantly better audiomet- 
ric performance than ears from unilaterally implanted ones: mean PTA $24 \mathrm{~dB} \pm 7$ vs $30 \mathrm{~dB} \pm 7$ (Mann Whitney $\mathrm{p}=0.001)$, SRT $27 \mathrm{~dB} \pm 8$ vs $37 \mathrm{~dB} \pm 13(\mathrm{p}<0.001)$, monosyllabic WRS $65 \% \pm 25$ vs $57 \% \pm 30(\mathrm{p}>0.05)$, disyllabic WRS $75 \% \pm 25$ vs $61 \% \pm 29(\mathrm{p}=0.037)$ and CID sentences score $88 \% \pm 20$ vs $74 \% \pm 26(\mathrm{p}=0.002)$.

\section{CT findings}

The CT results of the 35 otosclerotic ears are noted in Table I. Five ears (14.3\%) had only fenestral disease (grade 1), 11 ears $(31.4 \%)$ had a localised retrofenestral disease (grade 2) and 19 ears (54.3\%) had a diffuse retrofenestral disease with or without fenestral damage (grade 3).

There were no significant differences in hearing outcomes between the 3 grades (Kruskal-Wallis $p>0.05$ ) although patients from grades 2 and 3 showed poorer performances on all the scores. The division into fenestral (grade 1) and retrofenestral (grades 2 and 3) categories showed a significantly lower disyllabic WRS for patients with retrofenestral involvement on CT scan $(68 \% \pm 13$ vs $51 \% \pm 28$, Mann-Whitney $\mathrm{p}=0.023$ ).

Although surgical difficulties and facial symptomatology were most encountered in CT grade 2 and 3, no significant correlation could be shown between the retrofenestral damage on CT scan and these adverse effects (Fischer's exact test $\mathrm{p}=0.64$ and $\mathrm{p}=0.62$ ).

\section{Discussion}

Our results reaffirm that cochlear implantation constitutes an efficient solution in patients with FAO. Indeed, our findings revealed no difference between FAO and non-FAO implanted patients on standard measures such as disyllabic and CID sentences at 12 months. Scores were similar to those encountered in the literature 4691516 . However, it is noteworthy that analysis of monosyllabic WRS uncovered significant differences between groups and subgroups not otherwise revealed in other studies. We found a significantly lower monosyllabic WRS in the FAO group than in the non-FAO group, and within the former group we found a lower monosyllabic WRS for patients who underwent previous stapedotomy. The discrepancy between disyllabic and monosyllabic results can be partly explained by the well-known ceiling effect with disyllabic or sentences scores in quiet ${ }^{17}$. In our study, $23 \%$ and $35 \%$ of subjects scored $100 \%$ on the disyllabic and CID sentence recognition test, respectively, compared with only $8 \%$ of subjects who achieved the maximum score on the monosyllabic WRS. In contrast, in a small population, Castillo et al. ${ }^{4}$ noted a statistically better monosyllabic
WRS for FAO patients. Sainz et al. ${ }^{6}$ found a similar trend as we have, though it was not statistically significant. In order to improve outcomes for implantation in post-stapedotomy FAO patients, it would be helpful to confirm our result in a larger sample and to determine the extent to which differences in speech understanding are related to pathophysiologic factors.

Several authors now recommend stapedotomy before potential cochlear implantation in FAO patients. This attitude has been reinforced by a recent meta-analysis on stapedotomy in cochlear implant candidates with FAO. In that study, van Loon et al. ${ }^{18}$ showed that in 60 of 83 patients $(72 \%)$, post-operative speech recognition scores with hearing aid were higher than 50\% after stapedotomy, and those patients were actually no longer CI candidates. Their mean speech recognition score after stapedotomy was 59\% (including words or sentences, monosyllabic, and disyllabic tests), which can be compared to the mean monosyllabic, disyllabic and sentences post-implantation scores reported in the present study of 53\%, 68\% and $76 \%$ respectively.

Regarding prognosis for patients who need cochlear implantation after stapedotomy, our results for monosyllabic WRS contradict the general consensus, based on disyllabic WRS ${ }^{10}$, that stapedotomy does not compromise further cochlear implantation ${ }^{9}$. Furthermore, it is noteworthy that in this study patients with stapedotomy were older at time of implantation and tended to present with a higher grade of severity on CT scan. This could be explained by the initial effectiveness of stapedotomy plus hearing aids that may delay cochlear implantation.

In this study, we chose stringent radiographic criteria for diagnosis of otosclerosis. As expected, our FAO patient distribution within $\mathrm{CT}$ grade differs from other studies as we did not consider those with normal CT scan as otosclerotic patients. Nevertheless, the trend was similar, as most of the patients $(86 \%)$ who required cochlear implant had retrofenestral involvement 10111316 .

To date, there is no universally accepted computed tomography classification for otosclerosis. Rotteveel's criteria rely on histological extension of the otosclerotic lesion to the footplate, cochlear endosteum, and otic capsule. This type of classification was initially created to evaluate stapedotomy as treatment of otosclerosis. Although it is inspired by several histological studies that revealed discrepancies in the association between localization of anatomical foci and hearing outcomes or facial nerve stimulation ${ }^{112} 19$, Rotteveel et al. showed no correlation between duration of sensorineural hearing loss and endosteum extension, though extension was associated with a younger age at deafness onset ${ }^{13}$. In our study, the severity 
of the CT scan grade seemed to be related to poorer auditory outcomes, but this relationship was not statistically significant. However, the trend was statistically confirmed with analysis of the disyllabic WRS when CT grades were grouped into fenestral and retrofenestral categories, regardless of cochlear endosteum involvement, as proposed by Lagleyre et al. ${ }^{20}$ and Marx et al. ${ }^{12}$.

The distinction between fenestral and retrofenestral involvement allowed us to show that retrofenestral involvement is a negative predictive factor for disyllabic WRS. However, this radiological distinction did not predict surgical difficulties or facial nerve symptomatology. These results are contrary to the conclusions of Semaan et al. ${ }^{21}$, who showed in a similar study that the presence of CT scan (and especially retrofenestral) abnormalities did not predict hearing outcome in cochlear implantation for FAO. However, in that study, only $26.4 \%$ of the FAO patients had pre-operative radiographic abnormalities, which seems different from the reported sensitivity of $95 \%$ for CT scan findings of otosclerosis ${ }^{12}$. Furthermore, their results were based on a comparison between patients with and without CT scan abnormalities; our study instead evaluates different grades of lesions among only those patients who have pathological imaging.

Surgical difficulties such as cochlear ossification, incomplete electrode insertion and electrode misplacement seemed to be encountered more frequently in the FAO group (34\% vs $15 \%$ ) and especially in cases of retrofenestral involvement on CT scan, but our sample may be too small to find a statistically significant correlation between these rare complications and the aetiology of deafness. Overall complication rates in this review were less than or similar to most other studies ${ }^{6922}$.

Using solely straight electrodes, we observed facial nerve symptomatology in $8.6 \%$ of our patients with FAO, which is less than that shown in some other series $\left(25-75 \%{ }^{2324}\right)$, but similar to that obtained by Mosnier et al. and Sainz et al. ${ }^{615}$. However, one of our FAO patients required revision surgery for resistant facial nerve stimulation; as far as we know, this type of complication is quite rare as few cases are noted in the literature 52526 . In addition, within the FAO group, facial nerve symptomatology occurred only in patients with retrofenestral disease on CT scan. This is concordant with the hypothetical pathophysiology of facial nerve stimulation in otosclerotic implanted patients: otic capsule involvement on CT scan might be the radiologic translation of the histologic findings of this dysplastic bone between the facial nerve canal and the upper basal turn of the cochlea leading to decreased impedance between these structures ${ }^{211}$. Although not significant, this trend should be taken into account when warning otosclerotic patients of the potential risk of facial symptomatology.

Finally, we noticed higher scores from the ears of bilaterally implanted patients than from unilaterally implanted ones. We found no predictive factor in their demographic data. De Seta et al. ${ }^{27}$ showed that speech performance of the poorer ear continues to improve between 1 and 5 years after bilateral simultaneous implantation, whereas such an improvement is not observed after 1 year in unilateral implantation. One possible explanation could be related to the benefit of long-term increased stimulation of cortical auditory areas in bilaterally implanted patients ${ }^{2829}$. Nonetheless, we cannot ignore that there may be a sampling bias as our bilaterally implanted candidates were usually selected from good unilateral performers.

\section{Conclusions}

Based on standard evaluation scores, cochlear implantation in far advanced otosclerosis provides as good auditory outcomes as implantation in any aetiology. Even though surgical difficulties and complication rates are still low, they tend to be higher in patients with otosclerosis, especially in cases of severe extension shown by computed tomography. Patient information should be adjusted accordingly. Cochlear implantation in FAO patients can be considered as an effective and safe rehabilitation technique and should be proposed when stapedotomy and efficient hearing aids are no longer effective.

\section{Conflict of interest statement}

None declared.

\section{References}

1 Schuknecht HF, Barber W. Histologic variants in otosclerosis. Laryngoscope 1985;95:1307-17.

2 Kwok OT, Nadol JBJ. Correlation of otosclerotic foci and degenerative changes in the organ of Corti and spiral ganglion. Am J Otolaryngol 1989;10:1-12.

3 Rudic M, Keogh I, Wagner R, et al. The pathophysiology of otosclerosis: review of current research. Hear Res 2015;330:51-6.

4 Castillo F, Polo R, Gutierrez A, et al. Cochlear implantation outcomes in advanced otosclerosis. Am J Otolaryngol 2014;35:558-64.

5 Ramsay HA, Linthicum FHJ. Mixed hearing loss in otosclerosis: indication for long-term follow-up. Am J Otolaryngol 1994;15:536-9.

6 Sainz M, García-Valdecasas J, Garófano M, et al. Otosclerosis: mid-term results of cochlear implantation. Audiol Neurootol 2007;12:401-6. 
7 House HP, Sheehy JL. Stapes surgery: selection of the patient. Ann Otol Rhinol Laryngol 1961;70:1062-8.

8 Merkus P, van Loon MC, Smit CF, et al. Decision making in advanced otosclerosis: an evidence-based strategy. Laryngoscope 2011;121:1935-41.

9 Kabbara B, Gauche C, Calmels MN, et al. Decisive criteria between stapedotomy and cochlear implantation in patients with far advanced otosclerosis. Otol Neurotol 2015;36:73-8

10 Abdurehim Y, Lehmann A, Zeitouni AG. Stapedotomy vs cochlear implantation for advanced otosclerosis: systematic review and meta-analysis. Otolaryngol Head Neck Surg 2016;155:764-70.

11 Seyyedi M, Herrmann BS, Eddington DK, et al. The pathologic basis of facial nerve stimulation in otosclerosis and multi-channel cochlear implantation. Otol Neurotol 2013;34:1603-9.

12 Marx M, Lagleyre S, Escudé B, et al. Correlations between CT scan findings and hearing thresholds in otosclerosis. Acta Otolaryngol 2011;131:351-7.

13 Rotteveel LJC, Proops DW, Ramsden RT, et al. Cochlear implantation in 53 patients with otosclerosis: demographics, computed tomographic scanning, surgery, and complications. Otol Neurotol 2004;25:943-52.

14 Rotteveel LJC, Snik AFM, Cooper H, et al. Speech perception after cochlear implantation in 53 patients with otosclerosis: multicentre results. Audiol Neurotol 2010;15:128-36.

15 Mosnier I, Bouccara D, Ambert-Dahan E, et al. Cochlear implantation and far-advanced otosclerosis. Adv Otorhinolaryngol 2007;65:323-7.

16 Marshall AH, Fanning N, Symons S, et al. Cochlear implantation in cochlear otosclerosis. Laryngoscope 2005;115:1728-33.

17 Gifford RH, Shallop JK, Peterson AM. Speech recognition materials and ceiling effects: considerations for cochlear implant programs. Audiol Neurootol 2008;13:193-205.

18 van Loon MC, Merkus P, Smit CF, et al. Stapedotomy in co- chlear implant candidates with far advanced otosclerosis: a systematic review of the literature and meta-analysis. Otol Neurotol 2014;35:1707-14.

19 Elonka DR, Applebaum EL. Otosclerotic involvement of the cochlea: a histologic and audiologic study. Otolaryngol Head Neck Surg 1981;89:343-51.

20 Lagleyre S, Sorrentino T, Calmels MN, et al. Reliability of high-resolution CT scan in diagnosis of otosclerosis. Otol Neurotol 2009;30:1152-9.

21 Semaan MT, Gehani NC, Tummala N, et al. Cochlear implantation outcomes in patients with far advanced otosclerosis. Am J Otolaryngol 2012;33:608-14.

22 Sainz M, Garcia-Valdecasas J, Ballesteros JM. Complications and pitfalls of cochlear implantation in otosclerosis. Otol Neurotol 2009;30:1044-8.

23 Ruckenstein MJ, Rafter KO, Montes M, et al. Management of far advanced otosclerosis in the era of cochlear implantation. Otol Neurotol 2001;22:471-4.

24 Matterson AG, O'Leary S, Pinder D, et al. Otosclerosis: selection of ear for cochlear implantation. Otol Neurotol 2007;28:438-46.

25 Battmer R, Pesch J, Stover T, et al. Elimination of facial nerve stimulation by reimplantation in cochlear implant subjects. Otol Neurotol 2006;27:918-22.

26 Polak M, Ulubil SA, Hodges AV, et al. Revision cochlear implantation for facial nerve stimulation in otosclerosis. Arch Otolaryngol Head Neck Surg 2006;132:398-404.

27 De Seta D, Nguyen Y, Vanier A, et al. Five-year hearing outcomes in bilateral simultaneously cochlear-implanted adult patients. Audiol Neurootol 2016;21:261-7.

28 Fallon JB, Irvine DRF, Shepherd RK. Cochlear implants and brain plasticity. Hear Res 2008;238:110-7.

29 Coez A, Zilbovicius M, Ferrary E, et al. Brain voice processing with bilateral cochlear implants: a positron emission tomography study. Eur Arch Otorhinolaryngol 2014;271:3187-93.

Address for correspondence: Alix Ribadeau Dumas, Department of Otorhinolaryngology and Skull Base Surgery, Place Amélie Raba-Léon, Pellegrin University Hospital, 33076 Bordeaux, France. Tel. +33 556795532. Fax +33 556798768. E-mail: alix.ribadeaudumas@chu-bordeaux.fr 